\title{
Cerebral Mitochondrial Microangiopathy Leads to Leukoencephalopathy in Mitochondrial Neurogastrointestinal Encephalopathy
}

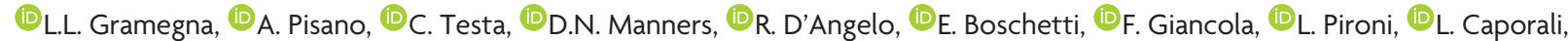

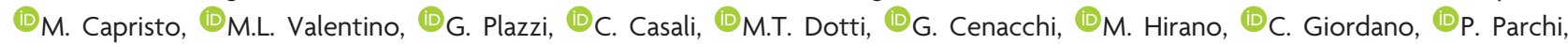

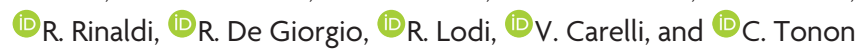 \\ o- E E
}

\begin{abstract}
BACKGROUND AND PURPOSE: Mitochondrial neurogastrointestinal encephalopathy is a rare disorder due to recessive mutations in the thymidine phosphorylase gene, encoding thymidine phosphorylase protein required for mitochondrial DNA replication. Clinical manifestations include gastrointestinal dysmotility and diffuse asymptomatic leukoencephalopathy. This study aimed to elucidate the mechanisms underlying brain leukoencephalopathy in patients with mitochondrial neurogastrointestinal encephalopathy by correlating multimodal neuroradiologic features to postmortem pathology.
\end{abstract}

MATERIALS AND METHODS: Seven patients underwent brain MR imaging, including single-voxel proton MR spectroscopy and diffusion imaging. Absolute concentrations of metabolites calculated by acquiring unsuppressed water spectra at multiple TEs, along with diffusion metrics based on the tensor model, were compared with those of healthy controls using unpaired $t$ tests in multiple white matters regions. Brain postmortem histologic, immunohistochemical, and molecular analyses were performed in 1 patient.

RESULTS: All patients showed bilateral and nearly symmetric cerebral white matter hyperintensities on T2-weighted images, extending to the cerebellar white matter and brain stem in 4 . White matter, $\mathrm{N}$-acetylaspartate, creatine, and choline concentrations were significantly reduced compared with those in controls, with a prominent increase in the radial water diffusivity component. At postmortem examination, severe fibrosis of brain vessel smooth muscle was evident, along with mitochondrial DNA replication depletion in brain and vascular smooth-muscle and endothelial cells, without neuronal loss, myelin damage, or gliosis. Prominent periependymal cytochrome C oxidase deficiency was also observed.

CONCLUSIONS: Vascular functional and histologic alterations account for leukoencephalopathy in mitochondrial neurogastrointestinal encephalopathy. Thymidine toxicity and mitochondrial DNA replication depletion may induce microangiopathy and blood-brain-barrier dysfunction, leading to increased water content in the white matter. Periependymal cytochrome $C$ oxidase deficiency could explain prominent periventricular impairment.

ABBREVIATIONS: $A D=$ axial diffusivity; $B W=$ brain water; $F A=$ fractional anisotropy; $M N G I E=$ mitochondrial neurogastrointestinal encephalopathy; mtDNA = mitochondrial DNA replication; $\mathrm{MD}=$ mean diffusivity; $\mathrm{PLIC}=$ posterior limbs of the internal capsule; $\mathrm{PO}-\mathrm{WM}=$ parieto-occipital white matter; $\mathrm{RD}=$ radial diffusivity

$\mathrm{M}^{\mathrm{i}}$ itochondrial neurogastrointestinal encephalopathy (MNGIE) is a rare autosomal recessive disorder due to mutations in the $T Y M P^{1}$ gene that result in thymidine phosphorylase deficiency. This causes toxic systemic elevation of thymidine and deoxyuridine levels,

Received July 23, 2017; accepted after revision October 30

From the Functional MR Unit (L.L.G., C.T., D.N.M., R.L., C.T.) and Neurology Unit (R.D., R.R.), S.Orsola-Malpighi Hospital, Bologna, Italy; Departments of Biomedical and Neuromotor Sciences (L.L.G., C.T., D.N.M., L.C., M.C., M.L.V., G.P., G.C., P.P., R.L., V.C., C.T.) and Surgical and Medical Sciences (E.B., F.G., L.P., R.D.G.), University of Bologna, Bologna, Italy; Departments of Radiology, Oncology, and Pathology (A.P., C.G.) and MedicoSurgical Sciences and Biotechnologies (C.C.), Sapienza, University of Rome, Rome, Italy Istituto di Ricovero e Cura a Carattere Scientifico Institute of Neurological Sciences (L.C., M.C., M.L.V., G.P., P.P., V.C.), Bologna, Italy; Department of Medicine, Surgery, and Neuroscience (M.T.D.), University of Siena, Siena, Italy; and Department of Neurology (M.H.), Columbia University Medical Centre, New York, New York.

Preliminary data for this study were previously presented at: Annual Meeting of the International Society of Magnetic Resonance in Medicine, Italian Chapter, October 24-25, 2013; Perugia, Italy. deoxynucleotide pool imbalance, and secondary mitochondrial DNA replication (mtDNA) abnormalities. ${ }^{2-5}$

Disease onset, typically in young adulthood, is characterized by a slowly progressive multisystemic involvement, which includes ptosis, chronic progressive external ophthalmoplegia with mitochondrial myopathy, demyelinating neuropathy, hearing

This study was supported by the Italian Ministry of Health with the grant RF-20091492481 ITA-MNGIE (to R.D.G.) to clarify main pathophysiologic, clinical, and therapeutic aspects of MNGIE.

Please address correspondence to Raffaele Lodi, MD, PhD, Functional MR Unit, S.Orsola-Malpighi Hospital, Via Massarenti 9, 40138 Bologna, Italy; e-mail: raffaele.lodi@unibo.it

- Indicates open access to non-subscribers at www.ajnr.org

$\equiv$ Indicates article with supplemental on-line appendix and table.

$\$ \triangle$ Indicates article with supplemental on-line photos.

http://dx.doi.org/10.3174/ajnr.A5507 
loss, and, most important, severe gastrointestinal dysmotility, leading to cachexia and diverticulosis of the small bowel. ${ }^{3,6}$

Severe mtDNA depletion is the most striking molecular defect affecting several tissues (ie, smooth muscle of the gastrointestinal wall and vasculature [small vessels]), suggesting that microvascular dysfunction may play a role in the pathogenesis. ${ }^{7,8}$ Although the skeletal muscle does not express thymidine phosphorylase, the toxic nucleoside accumulation results in a typical mitochondrial myopathy due to both depletion and accumulation of multiple deletions of mtDNA. ${ }^{2}$ Central nervous system involvement in MNGIE remains undercharacterized and puzzling. The brain neuroradiologic hallmark is leukoencephalopathy, with bilateral and symmetrically severe MR imaging signal alterations involving mostly cerebral hemispheric white matter. ${ }^{9,10}$ Remarkably, despite the extensive MR imaging alterations, most patients with MNGIE remain asymptomatic ${ }^{6}$; brain proton MR spectroscopy ( ${ }^{1} \mathrm{H}-\mathrm{MR}$ spectroscopy) studies of patients with MNGIE have shown white matter biochemical alterations suggesting either neuronal loss/dysfunction ${ }^{11,12}$ or a normal metabolic profile. ${ }^{13}$ Furthermore, a previous study reported increased water diffusivity, evaluated by diffusion-weighted MR imaging, in 4 patients with MNGIE. ${ }^{12}$ The neuropathologic study of 2 patients with genetically confirmed MNGIE did not show neuronal loss, demyelination, or glial proliferation, despite a striking loss of thymidine phosphorylase expression in capillaries of the white matter and an increased intracellular albumin staining, consistent with altered blood-brain barrier permeability. ${ }^{14}$

The purpose of this study was to elucidate the mechanisms underlying brain leukoencephalopathy in patients with MNGIE using a multimodal neuroradiologic and pathologic approach.

\section{MATERIALS AND METHODS}

\section{Patients}

Seven unrelated patients with a molecular diagnosis of MNGIE (3 men; age range, 23-38 years) were included in this study.

Patients were scanned on a $1.5 \mathrm{~T}$ MR imaging system (Signa Horizon LX; GE Healthcare, Milwaukee, Wisconsin). Quantitative MR imaging parameters were compared with those obtained from 9 healthy volunteers (4 men; age range, 20-35 years) who underwent white matter ${ }^{1} \mathrm{H}$-MR spectroscopy and from 14 healthy volunteers ( 7 men; age range, 21-43 years) who underwent diffusion tensor imaging. Patients were clinically assessed by neurologic, gastroenterologic, and nutritional evaluations. Four patients died, and in 1 patient (case 7), a postmortem examination was performed.

The Ethics Committee of S.Orsola-Malpighi Hospital approved the study, and written informed consent was obtained.

\section{Biochemical and Genetic Characterization}

Thymidine phosphorylase activity was assessed and quantified as previously reported. The TYMP gene was Sanger-sequenced. ${ }^{15}$

\section{Brain MR Imaging}

Conventional Brain MR Imaging Protocol Acquisition. Brain MR imaging was performed using a quadrature birdcage head coil. The conventional MR imaging protocol included an axial and coronal FLAIR T2 sequence, sagittal FSE T2, and axial FSE T1weighted imaging.
Proton MR Spectroscopy Protocol Acquisition. A volume of interest of $8 \mathrm{~cm}^{3}$ was selected in the left parieto-occipital white matter (PO-WM). Water-suppressed proton MR spectra were acquired using the point-resolved spectroscopy single-voxel localization sequence (PROBE) at $\mathrm{TE}=35,70,100,144$, and $288 \mathrm{~ms}$ $(\mathrm{TR}=4000 \mathrm{~ms}$, number of acquisitions $=64)$ to estimate the T2 of $\mathrm{N}$-acetylaspartate, creatine plus phosphocreatine, and cholinecontaining compounds ${ }^{16}$ for the group of healthy controls and for 3 of 7 patients.

For the remaining 4 patients, the left PO-WM spectrum was acquired only at $\mathrm{TE}=35 \mathrm{~ms}$ to limit the acquisition time to 4 minutes 16 seconds. In all subjects, unsuppressed water spectra were also acquired at $\mathrm{TE}=25,30,40,50,60,80,100,300,600$, 900, and $1000 \mathrm{~ms}$; with $\mathrm{TR}=15,000 \mathrm{~ms}$, as previously described, ${ }^{16}$ to evaluate the water signal and T2 water relaxation time.

Diffusion Tensor Imaging Protocol Acquisition. DTI was performed by a single-shot echo-planar imaging sequence using 6 noncollinear directions of the diffusion gradients with the following parameters: $\mathrm{TR}=10,000 \mathrm{~ms}, \mathrm{TE}=107 \mathrm{~ms}$, slice thickness $=$ $4 \mathrm{~mm}$ with a $2-\mathrm{mm}$ gap, voxel size $=1.25 \times 1.25 \times 6 \mathrm{~mm}^{3}$, b-value $=900 \mathrm{~s} / \mathrm{mm}^{2}$.

Proton MR Spectroscopy Data Analysis. Both suppressed and unsuppressed water spectra were processed with the fitting program LCModel (Version 6.3; http://www.lcmodel.com/). ${ }^{17}$ The exclusion criterion for ${ }^{1} \mathrm{H}-\mathrm{MR}$ spectroscopy metabolite evaluation was an LCModel estimated fitting error of $>20 \%$. The absolute concentrations of NAA and Cho were obtained using the T2 times of the metabolites calculated by fitting the monoexponential decay of their signal in the water-suppressed PROBE spectra at different TEs ${ }^{18}$ and estimating the intracellular water content by the biexponential fit of water signal amplitude of the unsuppressed water spectra as detailed in the On-line Appendix. We considered a $\mathrm{T} 2$ relaxation value reported in the literature for mIns $(150 \mathrm{~ms})^{19}$ because TE values used for water-suppressed spectra acquisitions are not sufficiently short to obtain an accurate signal T2-decay of this metabolite.

Diffusion Tensor Imaging Data Analysis. DTI processing was performed by using the FMRIB software library (FSL; http://www. fmrib.ox.ac.uk/fsl). DTI-EPI images were coregistered and corrected for eddy current and head movement effects using the FMRIB Linear Image Registration Tool (FLIRT; https://fsl. fmrib.ox.ac.uk/fsl/fslwiki/FLIRT). Parameter maps for mean diffusivity (MD), fractional anisotropy (FA), axial diffusivity (AD, $\left.\lambda_{1}\right)$, and radial diffusivity $\left[\mathrm{RD},\left(\lambda_{2}+\lambda_{3}\right) / 2\right]$ were determined voxelwise using the program DTIFit (https://fsl.fmrib.ox.ac.uk/ fsl/fslwiki/FDT/UserGuide\#DTIFIT). The EPI images were registered to the T1-weighted images using FSL tools.

To correlate the DTI-derived parameters with the biochemical profile, we defined an ROI on the DTI using the spatial coordinates of the spectroscopy volume of interest localized in the left PO-WM. Because in this ROI, WM fibers do not have a single predominant orientation, additional ROIs were defined on MD map images within white matter regions with high fiber directionality to assess changes in $\mathrm{AD}$ and $\mathrm{RD}$ with greater accuracy, namely the optic radiations, the posterior limbs of the internal 
Table 1: Demographic, genetic, and clinical features of patients with MNGIE

\begin{tabular}{|c|c|c|c|c|c|c|}
\hline $\begin{array}{l}\text { Case } \\
\text { No. }\end{array}$ & $\begin{array}{l}\text { Age at MRI } \\
(y r) / S e x\end{array}$ & TYMP Mutation $^{\mathrm{a}}$ & Mutation Type & TP Activity & $\begin{array}{c}\text { Age at } \\
\text { Neurologic Onset }\end{array}$ & $\begin{array}{c}\text { Age at } \\
\text { Gastroenterologic } \\
\text { Onset }\end{array}$ \\
\hline 1 & $23 / F$ & c.1249 dupC & Frame shift & Undetectable & 20 yr (ptosis/CPEO) & Childhood \\
\hline 2 & $29 / F$ & $\begin{array}{l}\text { c.1160-2A>G and } \\
\text { c.1382_1383insC }\end{array}$ & $\begin{array}{l}\text { Splice defect } \\
\text { Frame shift }\end{array}$ & Undetectable & Childhood (CPEO) & Childhood \\
\hline 3 & $28 / \mathrm{M}$ & $\begin{array}{c}c .215-1 \mathrm{G}>\mathrm{P} A \text { and } \\
\text { c. } 328 \mathrm{C}>\mathrm{T}\end{array}$ & $\begin{array}{l}\text { Splice defect } \\
\text { p. Q110X }\end{array}$ & Undetectable & 24 yr (ptosis/CPEO) & $20 \mathrm{yr}$ \\
\hline 4 & $27 / F$ & c.1160-1G >A & Splice defect & Very low & 20 yr (ptosis/CPEO) & Childhood \\
\hline 5 & $38 / \mathrm{M}$ & c. $522 \mathrm{~T}>\mathrm{A}$ & Splice defect & Undetectable & 37 yr (ptosis/CPEO) & $30 \mathrm{yr}$ \\
\hline 6 & $25 / M$ & c.1160-1G >A & Splice defect & Very low & $\begin{array}{l}25 \text { yr (peripheral } \\
\text { neuropathy) }\end{array}$ & $19 \mathrm{yr}$ \\
\hline 7 & $36 / M$ & c. $457 \mathrm{G}>\mathrm{A}$ & p. G153S & Undetectable & Childhood (ptosis) & $25 \mathrm{yr}$ \\
\hline
\end{tabular}

Note:-CPEO indicates chronic progressive external ophthalmoplegia; TP, thymidine phosphorylase.

${ }^{a}$ All homozygote.

${ }^{b}$ Main gastroenterologic symptoms included irritable bowel and/or functional dyspepsia-like symptoms.

capsule (PLIC), and the splenium of the corpus callosum (On-line Fig 1). The mean values of MD, FA, AD, and RD were calculated for each ROI.

\section{Statistical Analysis}

We first evaluated differences in demographic data between patients and controls, using a $t$ test or a Spearman $\chi^{2}$ test as appropriate. We performed a $t$ test for unpaired data to evaluate differences between patients and controls in quantitative MR imaging values, namely metabolite concentrations, water signals, $\mathrm{T}_{2 \text { brain water (BW) }}$ and $\mathrm{T}_{2 \mathrm{CSF}}$ water relaxation times and DTI parameters. Moreover, in the patient group, we performed a Spearman test to evaluate the correlation between MR spectroscopy metabolite values and DTI parameters. The threshold for significance for all analyses was set at $P<.05$.

\section{Postmortem Study}

The postmortem study was performed in patient 7, eight months after the MR imaging. Whole-body postmortem examination was performed within 24 hours of death. The brain was removed and fixed in $4 \%$ buffered formalin for neuropathologic examination.

\section{Histologic, Histochemical, and Immunohistochemical Analyses}

Tissue specimens including frontal, temporal, parietal, occipital, insular, and cingulate cortices; basal ganglia; thalamus; hippocampus; amygdala, brain stem (midbrain, pons, medulla oblongata); and several blocks of cerebellar hemispheres, including the dentate nucleus, and vermis, were obtained from formalinfixed brain tissue and used for histologic, histochemical, and immunohistochemical analyses. Six-micrometer-thick sections were stained with hematoxylin-eosin, periodic acid-Schiff, and periodic acid-Schiff plus diastase, Luxol fast blue, congo red, and PicroSirius Red. Immunohistochemical staining was performed using a large panel of antibodies (On-line Appendix).

\section{Molecular Analysis on Postmortem Brain Samples}

Paraffin brain sections from patient 7 and 3 age-matched controls (subjects who underwent postmortem examination for diagnostic purposes without clinical/pathologic evidence of central nervous system diseases) were subjected to laser capture microdissection with the MMI Nikon UV-CUT System (Molecular Ma- chines \& Industries, Glattbrug, Switzerland), as previously described $^{20}$ (also see the On-line Appendix).

\section{RESULTS}

Genetic diagnosis and biochemical features of patients with MNGIE are reported in Table 1.

\section{MR Imaging: Bilateral Altered White Matter Signal}

Brain MR imaging revealed a bilateral and nearly symmetric white matter involvement characterized by hyperintensity on FLAIR T2 and FSE T2 and hypointensity on T1-weighted sequences in all patients (Fig 1, On-line Fig 2, and On-line Table). Mild-to-severe frontal and parieto-occipital white matter involvement was detected in each patient. The temporal lobe white matter and basal ganglia were affected in 5 patients, and the cerebellar white matter and brain stem, in 4 . Three patients (cases 1,2, and 3) with milder brain involvement showed signal intensity changes exclusively localized in the deep periventricular cerebral white matter with normal signal intensity of the infratentorial structures.

\section{'H-MR Spectroscopy: Reduced Cerebral White Matter Metabolite Concentrations}

In PO-WM, patients showed a significant decrease of NAA, Cr, and Cho concentrations. mIns, which had the highest metabolite variability in patients with MNGIE, showed a trend toward reduced concentration (Fig 2). Metabolite ratios such as NAA/ $\mathrm{Cr}, \mathrm{Cho} / \mathrm{Cr}$, and $\mathrm{mIns} / \mathrm{Cr}$ were similar in patients and controls (Table 2).

$\mathrm{T}_{2 \mathrm{BW}}$ values, calculated from the fast decay component of the signal from unsuppressed water acquisitions and attributable to both the intracellular and intramyelin water compartments, were significantly higher in patients compared with controls (Table 3 and On-line Fig 3).

\section{DTI: Prominent Increase of White Matter Radial Diffusivity}

In the same PO-WM region selected for the MR spectroscopy acquisition, patients with MNGIE showed significantly higher $\mathrm{MD}, \mathrm{RD}$, and $\mathrm{AD}$ as well as significantly lower FA values compared with controls. The RD increase, relative to mean control values, was more prominent than the $\mathrm{AD}$ increase $\mathrm{RD},+52 \%$; $\mathrm{AD},+23 \%)$. Similar results were obtained in the optic radiations. 


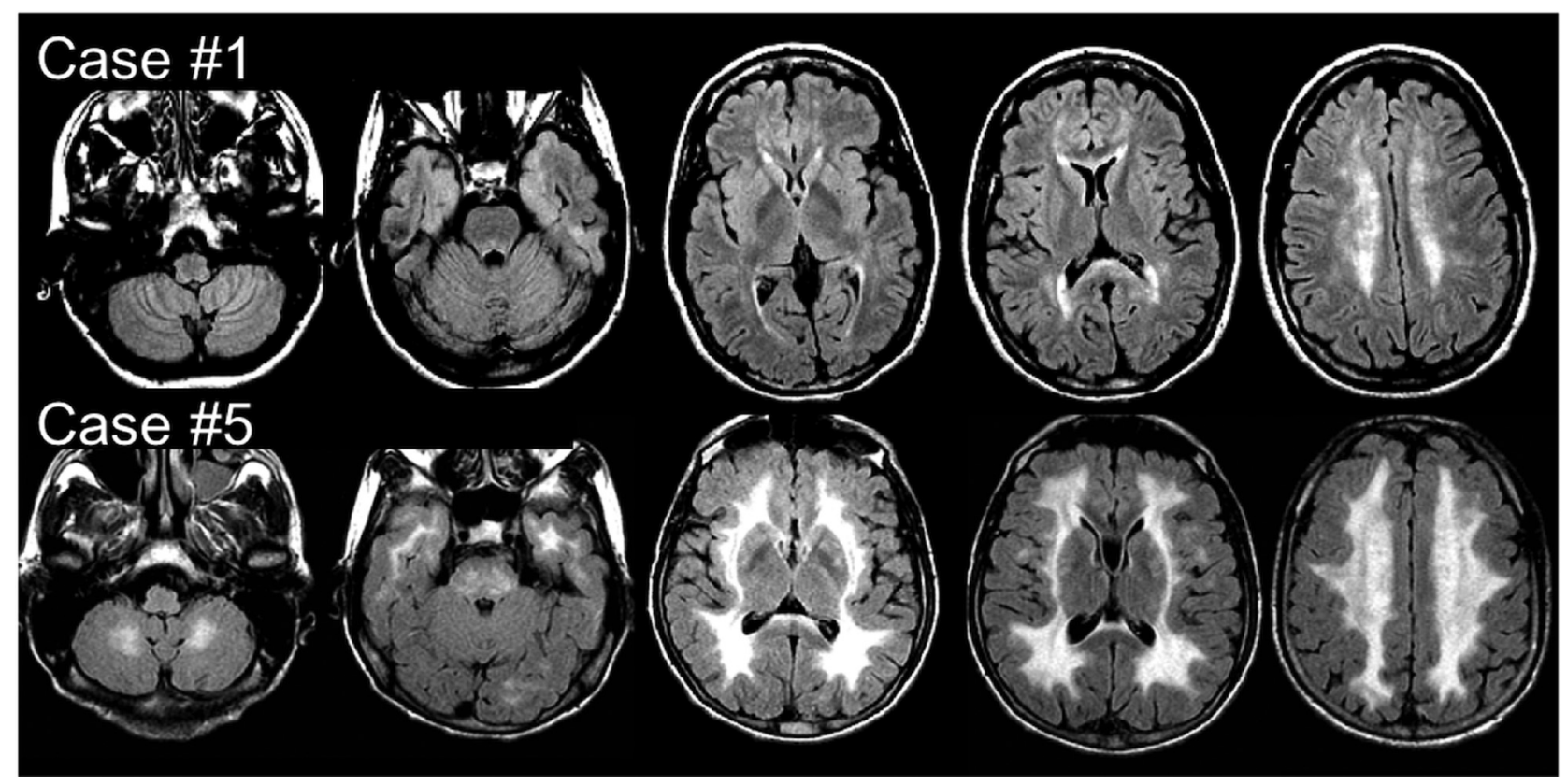

FIG 1. MR imaging. Axial FLAIR T2 images from 2 of the 7 patients with MNGIE at the supra- and infratentorial levels. Case 1 does not show any infratentorial involvement, while a more diffuse supra- and infratentorial signal intensity increase can be seen in case 5.

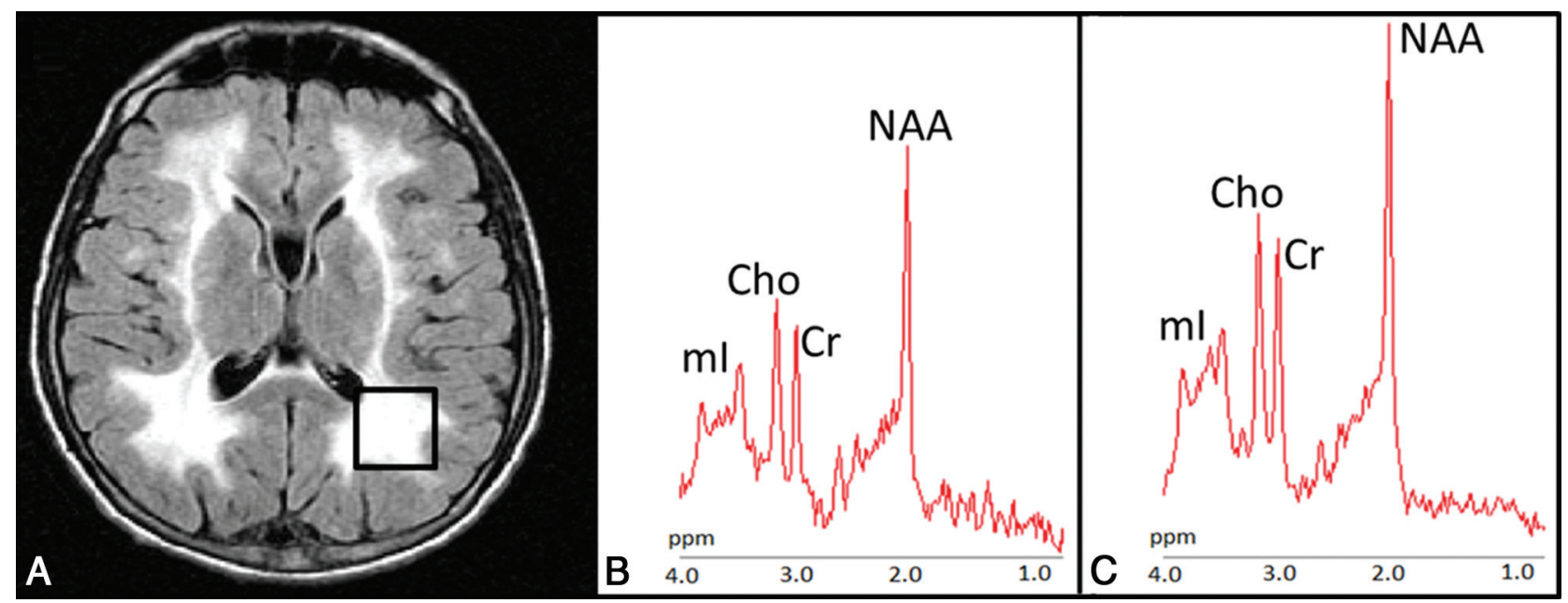

FIG 2. Proton MR spectroscopy. A, Axial FLAIR T2-weighted image shows the localization of the 8 - $\mathrm{cm}^{3}{ }^{1} \mathrm{H}-\mathrm{MR}$ spectroscopy volume of interest in the left parieto-occipital white matter in case 5. Proton MR spectra from the VOI in case $5(B)$ and in a healthy control (C). The relative content of metabolites is similar in the patient and healthy subject. Note the higher level of noise in the patient and smaller metabolite peaks.

In patients with MNGIE, the difference between $\mathrm{RD}$ and $\mathrm{AD}$ changes was even more evident in the PLIC and splenium of the corpus callosum, where a significant increase in $\mathrm{RD}$ values was associated with unchanged AD in both ROIs (Table 3).

Correlation analysis between metabolite concentrations and DTI metrics from the same PO-WM voxel in patients with MNGIE disclosed a negative correlation between NAA absolute concentration and $\mathrm{MD}(r=-0.82, P=.023), \mathrm{RD}(r=-0.82$, $P=.02)$, and $\mathrm{AD}$ values $(r=-0.89, P=.007)$.

\section{Neuropathology: Fibrosis of Small-Vessel Walls and Microbleeding}

Gross examination findings of the brain and vessels of the circle of Willis were unremarkable. Microscopic examination revealed a moderate pallor of the deep cerebral white matter extending fo- cally into the internal capsule and thalamic white matter, while sparing the arcuate fibers and the corpus callosum. These changes, however, were not associated with a significant gliosis, neuronal loss, or axonal degeneration. The gray matter was also unremarkable.

The most striking feature was observed at the level of small perforating arterioles, which showed a replacement of smoothmuscle cells of the tunica media by dense fibrous tissue (Fig $3 A-$ $C)$. Loss of smooth-muscle cells was more evident in the external layers of the tunica media (Fig $3 B$ ), though a total fibrous replacement was observed in some vessels (Fig 3C). These features were particularly frequent in the white matter of the frontal lobe, the basal ganglia, and the midbrain, but absent in pial arteries (not shown). Fibrosis was occasionally associated with concentric wall thickening and luminal narrowing (Fig 3D). In addition, hemo- 
Table 2: 'H-MRS white matter parieto-occipital metabolite absolute concentrations, ratios, and water signal intensity, and T2 values in patients with MNGIE and healthy controls

\begin{tabular}{|c|c|c|c|}
\hline & $\begin{array}{l}\text { Patients with } \\
\text { MNGIE ( } n=7) \\
\text { (mean } \pm \text { SD) }\end{array}$ & $\begin{array}{l}\text { Healthy Controls } \\
\qquad \begin{array}{c}(n=9) \\
\text { (mean } \pm \text { SD) }\end{array}\end{array}$ & $\begin{array}{c}P \\
\text { Value }^{\mathrm{a}}\end{array}$ \\
\hline \multicolumn{4}{|c|}{ Metabolite concentrations (mM) } \\
\hline NAA & $6.98 \pm 0.79$ & $9.81 \pm 0.94$ & $<.001^{\mathrm{a}, \mathrm{c}}$ \\
\hline $\mathrm{Cr}$ & $4.15 \pm 0.48$ & $5.97 \pm 0.55$ & $<.001^{\mathrm{a}, \mathrm{c}}$ \\
\hline Cho & $1.53 \pm 0.23$ & $1.89 \pm 0.24$ & $.01^{\mathrm{a}}$ \\
\hline mlns & $4.46 \pm 1.14$ & $5.44 \pm 0.76$ & $.06^{\mathrm{a}}$ \\
\hline \multicolumn{4}{|c|}{ Metabolite ratios } \\
\hline $\mathrm{NAA} / \mathrm{Cr}$ & $1.85 \pm 0.18$ & $1.80 \pm 0.11$ & $.57^{\mathrm{b}}$ \\
\hline $\mathrm{Cho} / \mathrm{Cr}$ & $0.39 \pm 0.06$ & $0.33 \pm 0.04$ & $.04^{\mathrm{b}}$ \\
\hline $\mathrm{mlns} / \mathrm{Cr}$ & $0.99 \pm 0.27$ & $0.85 \pm 0.08$ & $.16^{\mathrm{b}}$ \\
\hline \multicolumn{4}{|c|}{ Water signal (a.u.) } \\
\hline $\mathrm{S}_{\mathrm{BW}}(0)$ & $(14.0 \pm 9.0) \times 10^{10}$ & $(10.8 \pm 2.0) \times 10^{10}$ & .370 \\
\hline$S_{C S F}(0)$ & $(4.0 \pm 7.5) \times 10^{10}$ & $(1.3 \pm 0.6) \times 10^{10}$ & $.23^{\mathrm{a}}$ \\
\hline \multicolumn{4}{|l|}{ T2 water } \\
\hline $\mathrm{T}_{2 \mathrm{BW}}(\mathrm{ms})$ & $112 \pm 24$ & $75 \pm 8$ & $.001^{\mathrm{a}, \mathrm{c}}$ \\
\hline $\mathrm{T}_{2 \mathrm{CSF}}(\mathrm{ms})$ & $520 \pm 185$ & $776 \pm 344$ & $.098^{\mathrm{a}}$ \\
\hline
\end{tabular}

Note:- - a.u. indicates arbitrary units; $\mathrm{S}_{\mathrm{BW}}(0)$ and $\mathrm{S}_{\mathrm{CSF}}(0)$, water signals corresponding to brain and cerebrospinal water, respectively; $T_{2 B W}$ and $T_{2 C S F}$, water relaxation times corresponding to brain and cerebrospinal water, respectively.

a Statistical significance was set at $P<.0125$ after Bonferroni correction for multiple comparisons.

${ }^{\mathrm{b}}$ Statistical significance was set at $P<.0167$ after Bonferroni correction for multiple comparisons.

‘ Significant.

Table 3: DTI derivate metrics in patients with MNGIE and healthy controls

\begin{tabular}{|c|c|c|c|c|}
\hline ROI & MD (Mean \pm SD) & FA (Mean $\pm S D$ ) & $\mathrm{AD}$ (Mean $\pm \mathrm{SD}$ ) & $\mathrm{RD}($ Mean $\pm \mathrm{SD}$ ) \\
\hline \multicolumn{5}{|l|}{ PO-WM } \\
\hline MNGIE & $1.09 \pm 0.16$ & $0.27 \pm 0.05$ & $1.40 \pm 0.16$ & $0.93 \pm 0.16$ \\
\hline Controls & $0.79 \pm 0.05$ & $0.40 \pm 0.02$ & $1.14 \pm 0.07$ & $0.61 \pm 0.05$ \\
\hline$P$ Value $^{\mathrm{a}}$ & $<.0001^{\mathrm{b}}$ & $<.0001^{\mathrm{b}}$ & $.0001^{b}$ & $<.0001^{\mathrm{b}}$ \\
\hline \multicolumn{5}{|l|}{ OR } \\
\hline MNGIE & $1.15 \pm 0.20$ & $0.41 \pm 0.07$ & $1.69 \pm 0.19$ & $0.88 \pm 0.21$ \\
\hline Controls & $0.81 \pm 0.05$ & $0.59 \pm 0.09$ & $1.35 \pm 0.12$ & $0.54 \pm 0.06$ \\
\hline$P$ Value ${ }^{a}$ & $<.0001^{\mathrm{b}}$ & $.0003^{\mathrm{b}}$ & $.0002^{b}$ & $<.0001^{\mathrm{b}}$ \\
\hline \multicolumn{5}{|l|}{ PLIC } \\
\hline MNGIE & $0.78 \pm 0.06$ & $0.61 \pm 0.07$ & $1.40 \pm 0.06$ & $0.47 \pm 0.08$ \\
\hline Controls & $0.69 \pm 0.05$ & $0.70 \pm 0.04$ & $1.36 \pm 0.11$ & $0.35 \pm 0.05$ \\
\hline$P$ Value ${ }^{a}$ & $.0019^{\mathrm{b}}$ & $.0008^{\mathrm{b}}$ & 0.36 & $.0003^{b}$ \\
\hline \multicolumn{5}{|l|}{ CC } \\
\hline MNGIE & $0.88 \pm 0.08$ & $0.66 \pm 0.06$ & $1.64 \pm 0.11$ & $0.49 \pm 0.10$ \\
\hline Controls & $0.81 \pm 0.09$ & $0.76 \pm 0.06$ & $1.72 \pm 0.19$ & $.35 \pm 0.08$ \\
\hline$P$ Value ${ }^{a}$ & .12 & $.0012^{\mathrm{b}}$ & 0.37 & $.0028^{\mathrm{b}}$ \\
\hline
\end{tabular}

Note:-OR indicates optic radiation; CC, corpus callosum.

a Statistical significance was set at $P<.003$ after Bonferroni correction for multiple comparisons.

b Significant.

siderin-laden macrophages, consistent with previous microbleeding aspects, were observed close to fibrotic small vessels and capillaries (Fig 3E). Immunohistochemical stains revealed increased deposition of collagen IV in the basal lamina of several vessels (not shown) and a slight perivascular gliosis (Fig 3F). The endothelial layer, as observed by CD31 immunostaining, was unremarkable (not shown). Immunostaining for amyloid was negative (not shown).

Consistent with the mitochondrial etiology of the disease, scattered neurons showed decreased expression of the mtDNAencoded COX I subunit. This feature was particularly evident in the subependymal region of the lateral ventricles (not shown) and was paralleled by mtDNA depletion in different regions of the brain (frontal gray and white matter, and substantia nigra) and, most important, in microdissected vascular smooth-muscle and endothelial cells (Fig 4).

\section{DISCUSSION}

We documented that leukoencephalopathy, the hallmark of brain MR imaging in MNGIE, is characterized by dilution of all metabolites associated with a prominent increase of the radial component of water diffusion in multiple white matter regions. These results, obtained in 7 patients, combined with the postmortem findings in the brain of one of them, support the hypothesis that neuroradiologic abnormalities in MNGIE result from microvascular damage. Indeed, we found a diffuse replacement of the vascular wall by dense fibrous tissue and multiple perivascular microbleeds in the white matter of the frontal lobe, in the basal ganglia, and in the midbrain.

Pathologic features of vessels are reminiscent of those described in cerebral microvessel disease $e^{21-23}$ and point to impaired intracerebral blood flow regulation and blood-brain barrier permeability as synergic mechanisms leading to increased intracellular and intramyelin water content. The fibrosis of vascular smooth-muscle cells is in line with that observed in the external layer of the muscularis propria of the gastrointestinal tract, ${ }^{8}$ which is the main factor responsible for the severe dysmotility occurring in most patients with MNGIE. Analogous to observations in the muscularis propria and small vessels of the gastrointestinal wall, brain angiopathy is also characterized by a severe mtDNA depletion and COX deficiency, triggered by the toxic effects of high circulating levels of nucleosides. ${ }^{8}$ A previous brain neuropathologic study of 2 patients with MNGIE showed an increase of albumin immunoreactivity in the cytoplasm of reactive astrocytes compared with controls. ${ }^{14}$ This finding was interpreted as a result of a functional blood-brain barrier alteration, as suggested by the embryogenic role played by TYMP in glial proliferation. ${ }^{24}$

In all our patients, brain MR imaging demonstrated a typical, diffuse (mild-to-severe) leukoencephalopathy, in striking contrast to the absence of clinical central nervous system involvement, as observed in previously reported patients. ${ }^{6}$ In particular, in mildly affected patients, MR imaging signal alterations were confined to the subependymal deep cerebral white matter, while in the severely affected patients, these changes extended to the subcortical white matter, deep gray matter, and subtentorial structures. This gradient of MR imaging white matter abnormalities parallels the prominent COX deficiency seen in case 7 in the periependymal tissue, which may be damaged first by high CSF levels of thymidine.

${ }^{1} \mathrm{H}$-MR spectroscopy of the cerebral white matter of patients 

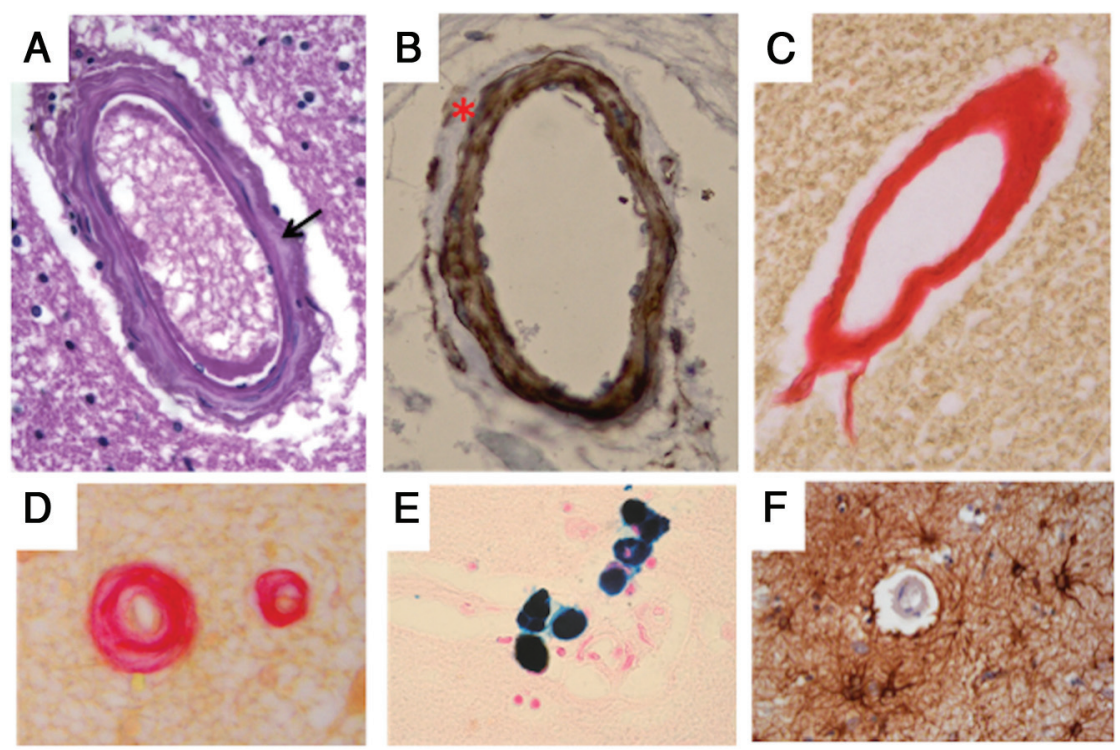

FIG 3. Histologic features of brain vessels in patient 7 with MNGIE. A, Representative image of a penetrating arteriole showing increased collagen deposition in the tunica media (arrow) (H\&E, original magnification $\times 40$ ). $B$, Loss of smooth-muscle cells of the tunica media in a penetrating vessel, especially evident at the outermost layer (smooth-muscle actin, original magnification $\times 40$ ). C, A thick fibrous coat completely replaces the 3-layer structure of a penetrating vessel (PicroSirius Red, original magnification $\times 40$ ). $D$, Fibrous replacement is associated with luminal narrowing in a small brain vessel (PicroSirius Red, original magnification $\times 40$ ). E, Perl iron stain consistent with hemosiderin deposits close to a brain capillary (Perls stain, original magnification $\times 40)$. F, Perivascular gliosis (glial fibrillary acidic protein, original magnification $\times 40$ ). with MNGIE showed significant reductions of NAA, Cho, and Cr concentrations. The increase of the T2 of the water signals, derived from a slower decay of the unsuppressed water signal at a short TE (26-300 ms), may be attributed to both intramyelinic and intracellular water. ${ }^{25}$ The significant increase in $\mathrm{T} 2$ of intracellular water of patients compared with controls suggests the enlargement of the intracellular compartment and consequently supports the hypothesis of a dilution effect underpinning the decreased metabolite concentrations. Previous ${ }^{1} \mathrm{H}-\mathrm{MR}$ spectroscopy studies performed on 7 patients with MNGIE suggested unchanged metabolite ratios in the cerebral white matter. ${ }^{11-13}$ For the first time, we provide absolute metabolite quantification by acquiring unsuppressed water spectra at multiple TEs, to distinguish intra- from extracellular water. ${ }^{18}$

In our patients with MNGIE, the DTI metrics in the same parieto-occipital voxel of the ${ }^{1} \mathrm{H}-\mathrm{MR}$ spectroscopy study showed an increase of mean diffu-
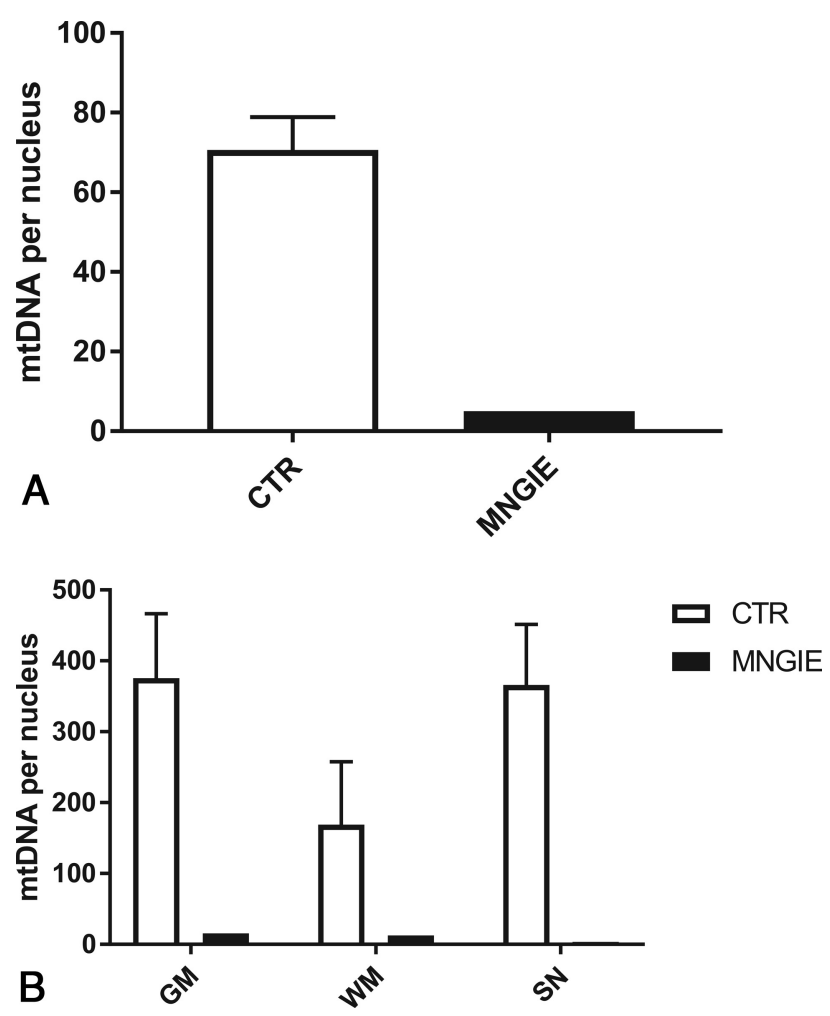

FIG 4. The mtDNA amount in the brain of patient 7 with MNGIE. A, mtDNA amount in smooth-muscle and endothelial cells microdissected by laser capture from an MNGIE brain and controls $(n=3)$ (expressed as mtDNA copy per nucleus). $B$, The mtDNA amount in different cerebral regions microdissected by laser capture from MNGIE and controls $(n=3)$ (expressed as mtDNA copy per nucleus). SN indicates substantia nigra; CTR, controls. sivity and a decrease of fractional anisotropy values, with a more prominent involvement of the radial than longitudinal diffusivity. To better estimate variations in axial and radial diffusivity, considering the abundance of white matter crossing fibers in the parieto-occipital voxel, we also evaluated DTI metrics in WM tracts with high fiber directionality, such as the optic radiations, PLIC, and splenium of corpus callosum. In all these structures, a prominent increase of radial diffusivity was confirmed (Table 3). ROIs of the splenium of the corpus callosum and PLIC showed a selective increase in radial diffusivity with unchanged axial diffusivity. Radial diffusivity is considered a measure of myelin integrity, ${ }^{26}$ as demonstrated by its selective increase in the corpus callosum of animal models with cuprizone-induced demyelination ${ }^{27,28}$ and in the optic nerves of mice with demyelination resulting from retinal ischemia. ${ }^{29}$ Similarly, in patients with relapsing-remitting multiple sclerosis, tract-specific DTI analysis of the optic radiations showed selective increases in RD only within the T2 lesions and, therefore, related to local myelin disruption. ${ }^{30}$

The absence of demyelination at postmortem examination in one of our patients with MNGIE as well as in the other 2 previously reported cases ${ }^{14}$ points to increased intramyelin water content as the most likely explanation for prominent or selective radial diffusivity found in brain white matter structures in our patients. A negative correlation between $\mathrm{N}$-acetylaspartate concentration and mean diffusivity values within the same white matter volume was demonstrated, supporting the hypothesis of a dilution effect as the basis of the metabolite concentration reduction, possibly affecting neuronal cells, because no correlation was observed between any other metabolite concentration expressed in either neural or glial cells and any DTI metrics. 
In addition to fibrous replacement of the vascular wall, the neuropathologic study revealed multiple microbleeds in the white matter of the frontal lobe, basal ganglia, and midbrain. None of the MNGIE T2-weighted images revealed foci of local signal loss consistent with the presence of hemosiderin deposits, ${ }^{31}$ though sequences such as gradient-echo $\mathrm{T} 2{ }^{*}$-weighted susceptibilityweighted imaging, the most sensitive MR imaging for the detection of hemosiderin deposits, ${ }^{32}$ were not acquired. However, the neuroradiologic and clinical features characterizing small-vessel disease, such as lacunar strokes and progressive cognitive decline, ${ }^{33}$ were absent in all our patients, suggesting key differences of small-vessel involvement in MNGIE compared with other conditions.

\section{CONCLUSIONS}

White matter metabolic and microstructural alterations detected in patients with MNGIE can be related to microangiopathy in the deep white matter and an energy metabolism deficit in the subependymal cells. Leukoencephalopathy in MNGIE may be the result of endothelial failure due to thymidine toxicity and mtDNA depletion, which may induce blood-brain barrier dysfunction and microangiopathy, leading to increased white matter water content. The question of whether leukoencephalopathy is a reversible feature cannot be solved at present. Long-term follow-up of patients with bone marrow ${ }^{34,35}$ and liver transplantation ${ }^{36}$ will likely provide an answer.

Disclosures: Giuseppe Plazzi-UNRELATED: Board Membership: Jazz Pharmaceuticals, UCB, BioProject. Roberto De Giorgio—RELATED: Grant: RF-2009-1492481 ITA MNGIE*. Valerio Carelli-UNRELATED: Consultancy: GenSight, Santhera Pharmaceuticals; Other: GenSight and Santhera Pharmaceuticals, Comments: clinical trial on Leber Hereditary Optic Neuropathy*. Michio Hirano_UNRELATED: Grant: National Institutes of Health*, Comments: for a Phase I safety study of bone marrow transplant for MNGIE. *Money paid to the institution.

\section{REFERENCES}

1. Nishino I, Spinazzola A, Hirano M. Thymidine phosphorylase gene mutations in MNGIE, a human mitochondrial disorder. Science 1999;283:689-92 CrossRef Medline

2. Nishigaki Y, Martí R, Copeland WC, et al. Site-specific somatic mitochondrial DNA point mutations in patients with thymidine phosphorylase deficiency. J Clin Invest 2003;111:1913-21 CrossRef Medline

3. Hirano M, Nishigaki Y, Martí R. Mitochondrial neurogastrointestinal encephalomyopathy (MNGIE): a disease of two genomes. $\mathrm{Neu}$ rologist 2004;10:8-17 CrossRef Medline

4. Spinazzola A, Marti R, Nishino I, et al. Altered thymidine metabolism due to defects of thymidine phosphorylase. J Biol Chem 2002; 277:4128-33 CrossRef Medline

5. Martí R, Nishigaki Y, Hirano M. Elevated plasma deoxyuridine in patients with thymidine phosphorylase deficiency. Biochem Biophys Res Commun 2003;303:14-18 CrossRef Medline

6. Garone C, Tadesse S, Hirano M. Clinical and genetic spectrum of mitochondrial neurogastrointestinal encephalomyopathy. Brain 2011;134(Pt 11):3326-32 CrossRef Medline

7. Giordano C, Sebastiani M, Plazzi G, et al. Mitochondrial neurogastrointestinal encephalomyopathy: evidence of mitochondrial DNA depletion in the small intestine. Gastroenterology 2006;130:893-901 CrossRef Medline

8. Giordano C, Sebastiani M, De Giorgio R, et al. Gastrointestinal dysmotility in mitochondrial neurogastrointestinal encephalomyopathy is caused by mitochondrial DNA depletion. Am J Pathol 2008; 173:1120-28 CrossRef Medline
9. Nishino I, Spinazzola A, Hirano M. MNGIE: from nuclear DNA to mitochondrial DNA. Neuromuscul Disord 2001;11:7-10 CrossRef Medline

10. Millar WS, Lignelli A, Hirano M. MRI of five patients with mitochondrial neurogastrointestinal encephalomyopathy. Am J Roentgenol 2004;182:1537-41 CrossRef Medline

11. Schüpbach WM, Vadday KM, Schaller A, et al. Mitochondrial neurogastrointestinal encephalomyopathy in three siblings: clinical, genetic and neuroradiological features. J Neurol 2007;254:146-53 CrossRef Medline

12. Scarpelli M, Ricciardi GK, Beltramello A, et al. The role of brain MRI in mitochondrial neurogastrointestinal encephalomyopathy. $\mathrm{Neu}$ roradiol J 2013;26:520-30 CrossRef Medline

13. Rousset P, Elmaleh-Bergès M, Ogier de Baulny H, et al. Mitochondrial neurogastrointestinal encephalomyopathy [in French]. J Neuroradiol 2008;35:121-24 CrossRef Medline

14. Szigeti K, Sule N, Adesina AM, et al. Increased blood-brain barrier permeability with thymidine phosphorylase deficiency. Ann Neurol 2004;56:881-86 CrossRef Medline

15. Mohamed S, Caporali L, De Giorgio R, et al. HPLC-UV analysis of thymidine and deoxyuridine in plasma of patients with thymidine phosphorylase deficiency. J Chromatogr B Analyt Technol Biomed Life Sci 2014;949-950:58-62 CrossRef Medline

16. Malucelli E, Manners DN, Testa C, et al. Pitfalls and advantages of different strategies for the absolute quantification of $\mathrm{N}$-acetyl aspartate, creatine and choline in white and grey matter by $1 \mathrm{H}-\mathrm{MRS}$. NMR Biomed 2009;22:1003-13 Medline

17. Provencher SW. Automatic quantitation of localized in vivo $1 \mathbf{H}$ spectra with LCModel. NMR Biomed 2001;14:260-64 CrossRef Medline

18. Kreis R, Ernst T, Ross BD. Development of the human brain: in vivo quantification of metabolite and water content with proton magnetic resonance spectroscopy. Magn Reson Med 1993;30:424-37 CrossRef Medline

19. Kreis R, Slotboom J, Hofmann L, et al. Integrated data acquisition and processing to determine metabolite contents, relaxation times, and macromolecule baseline in single examinations of individual subjects. Magn Reson Med 2005;54:761-68 CrossRef Medline

20. Giordano C, d'Amati G. Evaluation of gastrointestinal mtDNA depletion in mitochondrial neurogastrointestinal encephalomyopathy (MNGIE). Methods Mol Biol 2011;755:223-32 CrossRef Medline

21. Wardlaw JM, Smith C, Dichgans M. Mechanisms of sporadic cerebral small vessel disease: insights from neuroimaging. Lancet $\mathrm{Neu}$ rol 2013;12:483-97 CrossRef Medline

22. Pantoni L. Cerebral small vessel disease: from pathogenesis and clinical characteristics to therapeutic challenges. Lancet Neurol 2010;9:689-701 CrossRef Medline

23. Wardlaw JM. Blood-brain barrier and cerebral small vessel disease. J Neurol Sci 2010;299:66-71 CrossRef Medline

24. Wolburg H, Lippoldt A. Tight junctions of the blood-brain barrier: development, composition and regulation. Vascul Pharmacol 2002; 38:323-37 CrossRef Medline

25. MacKay A, Laule C, Vavasour I, et al. Insights into brain microstructure from the T2 distribution. Magn Reson Imaging 2006;24:515-25 CrossRef Medline

26. Aung WY, Mar S, Benzinger TL. Diffusion tensor MRI as a biomarker in axonal and myelin damage. Imaging Med 2013;5:427-40 CrossRef Medline

27. Song SK, Yoshino J, Le TQ, et al. Demyelination increases radial diffusivity in corpus callosum of mouse brain. Neuroimage 2005;26: 132-40 CrossRef Medline

28. Xie M, Tobin JE, Budde MD, et al. Rostrocaudal analysis of corpus callosum demyelination and axon damage across disease stages refines diffusion tensor imaging correlations with pathological features. J Neuropathol Exp Neurol 2010;69:704-16 CrossRef Medline

29. Sun SW, Liang HF, Le TQ, et al. Differential sensitivity of in vivo and ex vivo diffusion tensor imaging to evolving optic nerve injury in

AJNR Am J Neuroradiol 39:427-34 Mar 2018 www.ajnr.org

433 
mice with retinal ischemia. Neuroimage 2006;32:1195-204 CrossRef Medline

30. Klistorner A, Vootakuru N, Wang C, et al. Decoding diffusivity in multiple sclerosis: analysis of optic radiation lesional and non-lesional white matter. PLoS One 2015;10:e122114 CrossRef Medline

31. Greenberg SM, Vernooij MW, Cordonnier C, et al; Microbleed Study Group. Cerebral microbleeds: a guide to detection and interpretation. Lancet Neurol 2009;8:165-74 CrossRef Medline

32. Fazekas F, Kleinert R, Roob G, et al. Histopathologic analysis of foci of signal loss on gradient-echo $\mathrm{T} 2^{\star}$-weighted MR images in patients with spontaneous intracerebral hemorrhage: evidence of microangiopathy-related microbleeds. AJNR Am J Neuroradiol 1999;20: 637-42 Medline

33. Inzitari D, Pracucci G, Poggesi A, et al; LADIS Study Group. Changes in white matter as determinant of global functional decline in older independent outpatients: three-year follow-up of LADIS (leukoaraiosis and disability) study cohort. BMJ 2009;339:b2477 CrossRef Medline

34. Filosto M, Scarpelli M, Tonin P, et al. Course and management of allogeneic stem cell transplantation in patients with mitochondrial neurogastrointestinal encephalomyopathy. J Neurol 2012;259: 2699-706 CrossRef Medline

35. Halter JP, Michael W, Schüpbach M, et al. Allogeneic haematopoietic stem cell transplantation for mitochondrial neurogastrointestinal encephalomyopathy. Brain 2015;138:2847-58 CrossRef Medline

36. De Giorgio R, Pironi L, Rinaldi R, et al. Liver transplantation for mitochondrial neurogastrointestinal encephalomyopathy. Ann Neurol 2016;80:448-55 CrossRef Medline 